\title{
Role of Endotoxin and TNF in Developing NAFLD in Non-Obese Egyptian Patients
}

\author{
Ehab F. Mostafa1, Alaa A. Farag' ${ }^{1}$, Ashraf Metwally², Engy F. Tantawy ${ }^{3}$, Farida Omran ${ }^{4}$ \\ ${ }^{1}$ Internal Medicine Department, Faculty of Medicine, Zagazig University, Zagazig, Sharqueya, Egypt \\ ${ }^{2}$ Tropical Medicine Department, Faculty of Medicine, Zagazig University, Zagazig, Sharqueya, Egypt \\ ${ }^{3}$ Radiology Department, Faculty of Medicine, Zagazig University, Zagazig, Sharqueya, Egypt \\ ${ }^{4}$ Microbiology Department, Faculty of Medicine, Zagazig University, Zagazig, Sharqueya, Egypt \\ Email: hobanoh@yahoo.com,dr_alaafarag@yahoo.com, ametwally75@yahoo.com,dr_engy_tantawy@yahoo.com, \\ fomran79@yahoo.com
}

How to cite this paper: Mostafa, E.F., Farag, A.A., Metwally, A., Tantawy, E.F. and Omran, F. (2017) Role of Endotoxin and TNF in Developing NAFLD in NonObese Egyptian Patients. Journal of Biosciences and Medicines, 5, 7-15. https://doi.org/10.4236/jbm.2017.57002

Received: April 22, 2017

Accepted: July 9, 2017

Published: July 13, 2017

Copyright $\odot 2017$ by authors and Scientific Research Publishing Inc. This work is licensed under the Creative Commons Attribution International License (CC BY 4.0).

http://creativecommons.org/licenses/by/4.0/ (c) (†) Open Access

\begin{abstract}
Background and aim of the work: Non-alcoholic fatty liver disease (NAFLD) was considered the hepatic presentation of insulin resistance and obesity for a long time. Studies on lean weighted Asian subjects with NAFLD revealed that NAFLD pathogenesis may be multifactorial. NAFLD is associated with disturbances in gut flora and excess expression of inflammatory mediators. This study aims to find out the relation of endotoxins absorbed from gut and the tumor necrosis factor alpha with NAFLD in non-obese Egyptian patient in comparison to obese patients and healthy control subjects. Patients and methods: This study was performed on three groups group I: Patients with NAFLD and body mass index $<25 \mathrm{~kg} / \mathrm{m}^{2}$. Group II: Patients with NAFLD and body mass index $>25 \mathrm{~kg} / \mathrm{m}^{2}$. Group III: healthy control subjects. Results: Group I had significantly higher endotoxin, tumor necrosis factor(TNF) alpha and ALT than group II (endotoxin $11.7 \pm 1.7 \mathrm{ug} / \mathrm{L}$ vs $9.5 \pm 1.4$ ) (TNF $14.8 \pm$ 5.3 vs $11.3 \pm 3.3)($ ALT $67.8 \pm 5.3 \mathrm{IU} / \mathrm{L}$ vs $51.8 \pm 4.2)$. There was a highly significant correlation between TNF, endotoxin levels and level of liver enzymes in group I and II. Conclusion: Endotoxemia and TNF alpha may contribute in the pathogenesis of NAFLD especially in non-obese patients.
\end{abstract}

\section{Keywords}

NAFLD, NASH, TNF Alpha, Endotoxin, Insulin Resistance

\section{Introduction}

Non-alcoholic fatty liver disease (NAFLD) is a condition defined by the excessive accumulation of fat (steatosis) in the hepatocytes due to any cause other 
than excessive alcohol use [1]. Histologically, a subgroup of NAFLD patients has hepatic cellular injury and inflammation in addition to excess fat accumulation (steatohepatitis) non-alcoholic steatohepatitis (NASH). Although the simple steatosis in NAFLD does not correlate with increased short-term morbidity or mortality, the progression of this condition to NASH increases the risk of cirrhosis and liver cell failure markedly [2].

The exact cause of NAFLD/NASH is not clear yet, and it is almost not the same in every patient. It is can be linked to insulin resistance, obesity and the metabolic syndrome, some drugs like tamoxifen, amiodarone and aspirin, genetics and excessive consumption of soft drinks rich in fructose [3] [4].

While most literatures agree that NAFLD/NASH is just the hepatic expression of abdominal obesity, type 2 diabetes and insulin resistance, few studies have examined NAFLD in lean populations. Although Asians are less obese than Western people, the prevalence of NAFLD and metabolic syndrome is not lower. Fourteen Studies in the accident populations, liver histology performed for liver donors and automobile crash victims, have roughly found hepatic steatosis in $15 \%$ of lean subjects, as opposed to $65 \%$ and $85 \%$ in obese and morbidly obese, respectively [5]. The reality of developing countries seems to be different, with a recent study in India showing that in a rural population with low prevalence of NAFLD, 75\% of NAFLD patients had a body mass index lower than $25 \mathrm{~kg} / \mathrm{m}^{2}$ and 54\% had neither overweight nor abdominal obesity [6].

Obesity and the metabolic syndrome have been found to be associated with disturbances in the gut bacterial flora. Gut bacteria can induce a higher extraction of energy from diet and change whole-body lipid metabolism shifting it from oxidation to production. NAFLD has been associated with small intestinal bacterial overgrowth and increased intestinal permeability [7] [8] that can result in an increase in endotoxin, lipopolysaccharide (LPS) and absorption from gut. Therefore, the possibility that intestinal bacterial products contribute to hepatic TNF- $\alpha$ induction in human NASH has not been excluded. The role of gut bacteria in human NASH pathogenesis is supported by the results of a recent study which found improvement in liver enzymes in NASH patients treated with oral probiotics [9].

LPS (endotoxin) activates the innate immune pathway through stimulation of toll-like receptors (TLRs) pattern recognition receptors, enabling a rapid reaction to infection, and represents the first line of defense against gram-negative infections [10]. This, in turn, induces the expression of inflammatory mediators (adipocytokines) such as tumor necrosis factor- $\alpha$ (TNF $\alpha$ ), leptin and interleukin-6 (IL-6), amongst others [9]. TLR's are present on the hepatic immune cells Kupffer cells, being the organ that is responsible for clearing up toxins from the gut. Endotoxins stimulate Kupffer cells to produce these inflammatory cytokines that will lead to NAFLD/NASH [11] [12].

In our study we aim to investigate the relation between NAFLD, endotoxemia and TNF level in serum in both obese and non-obese patients through measuring the levels of endotoxin and TNF in these patients and finding their correla- 
tion with the liver enzyme. Knowing such a relation between endotoxemia and NAFLD changes the concepts about treatment. If gut bacteria play a role in the pathogensis of NAFLD then a course of antibiotic or use of probiotics to change the type of gut flora can help with NAFLD treatment.

\section{Patients and Methods}

\section{Site and time of the study:}

This study was carried out in the departments of Tropical Medicine and Internal Medicine, Zagazig University Hospitals, in the period between January 2015 and March 2016.

\section{(1) Study subjects:}

\section{Inclusion criteria:}

Patients with NAFLD diagnosed by ultrasound criteria, selected randomly from patients attending the outpatient clinics.

\section{Exclusion criteria:}

- Patients $<18$ and $>60$

- Patients who refused to give an informed consent.

- Patients who had history of alcohol intake.

- Patient who experienced dieting or bariatric surgery and massive rapid weight loss.

- Diabetic patients.

- Patients with chronic liver disease due to other causes like viral, autoimmune, metabolic, biliary or drug induced.

- Patients with malignancy.

Sample size calculation: Was calculated at confidence interval of $95 \%$, at $80 \%$ power, error of $5 \%$, using (epi-info version 6)

The following was done to all patients:

- Full history taking: including history of diagnosed liver disease, diabetes, alcohol consumption and drug intake.

- Thorough clinical examination: including calculation of body mass index $(\mathrm{BMI})=$ weight $($ in $\mathrm{kg}) /$ height $^{2}$ (in meters)

- The patients were allocated into two groups according to their BMI and a third group of healthy control subjects was randomly selected from healthy blood donors.

Group I: 32 lean weighted patients diagnosed with NAFLD; body mass index $<25 \mathrm{Kg} / \mathrm{m}^{2}$

Group II: 40 obese patients diagnosed with NAFLD; body mass index > 25 $\mathrm{Kg} / \mathrm{m}^{2}$

Group III: 20 healthy control subjects

\section{(2) NAFLD diagnosis:}

Abdominal ultrasound for diagnosis of NAFLD was done by same experienced operator. using a Toshiba CAPASEE II device (Toshiba, Japan) equipped with a broad band $2.5-5 \mathrm{MHz}$ curved-array probe to assess the presence of liver steatosis (bright liver), which was defined and graded as follows: (a) a diffuse 
hyperechoic echo texture (bright liver), (b) increased liver echo texture compared with the kidney, (c) vascular blurring, and (d) deep attenuation 8. Steatosis was graded using this semiquantitative scale from 1 to 4 . Fibrosis, when present with noticeable steatosis, was identified by a coarse echo pattern. Therefore, the grade fibro-fatty indicated the presence of a bright liver, with a coarse texture [13].

(3) Liver functions and lipid profile assessment:

Liver function tests, liver transaminases, lipid profile; cholesterol and triglycerides by were done on ARRAY 360 using kit supplied by Beckman. Viral markers and autoimmune markers were done by ELISA.

(4) Measurement of fasting blood sugar and insulin and HOMA calculation:

Fasting blood sugar was done using hexokinase method on auto analyzer synchron CX 5 using kit supplied by Beckman.

Fasting serum insulin was done by ARRAY 360 using kit supplied by Beckman.

Calculation of homeostasis model assessment for insulin resistance, HOMA IR = fasting glucose $(\mathrm{mg} / \mathrm{dl}) \times$ fasting insulin $\mathrm{mU} / \mathrm{L} / 405[14]$.

(5) Measurement of tumor necrosis factor alpha (TNF):

The concentrations $\mathrm{n}$ TNF-alpha in blood serum was measured using a commercially available highly sensitive ELISA kits (Genzyme Diagnostics, Cambridge, USA). The detection limits for the TNF-alpha was $3.0 \mathrm{pg} / \mathrm{ml}$. The interassay and the intra-assay coefficients of variation were less than $8.8 \%$.

(6) Measurement of lipopolysaccride or endotoxin (LPS):

Serum lipopolysacchride concentration was measured by endotoxin assay, based on a Limulus amebocyte extract with a chromogenic Limulus amebocyte lysate (LAL) assay (QCL-1000, Lonza Group Ltd.). Samples were diluted in pyrogen-free water and heated at $70^{\circ} \mathrm{C}$ for $10 \mathrm{~min}$ to inactivate endotoxin-neutralizing agents that inhibit the activity of endotoxin in the LAL assay. Internal control of recovery calculation was included in the assessment. All samples were tested in duplicate. The endotoxin content was expressed as endotoxin units $(\mathrm{EU}) / \mathrm{mL}$. Care was taken to avoid environmental endotoxin contamination and all material used for sample preparation. Plasma LPS-binding protein (LBP) levels were determined by a sandwich enzyme-linked immunosorbent assay Technology. Plasma samples were diluted at least 200 times and assayed according to the manufacturer's instructions. The assay has a sensitivity of $0.2 \mathrm{ng} / \mathrm{ml}$. The intra-assay and inter assay coefficients of variation were $<5 \%$ and $<10 \%$, respectively.

\section{Statistical analysis:}

Data were calculated by SPSS (epi-info version 6). Numerical data were presented as mean and standard deviation while categorical data were presented as number and percentage. Comparison of numerical data was done using ANOVA and chi-square test was used to compare categorical data. Pearson correlation was used to estimate correlations between two numerical variants. The $\mathrm{P}$ value 
was considered significant if it was less than 0.05 .

\section{Results}

Table 1 shows that there were no significant differences between the studied groups as regards age or gender distribution. Group II had significantly higher mean BMI value compared to the other two groups. Table 2 shows that group I had significantly higher alanine transaminase (ALT) and aspartate transaminase (AST) levels than the other two groups followed by group II. And that group II had significantly higher triglyceride level, fasting blood sugar (FBS), HOMA IR value than the other two groups followed by group I.

Table 3 shows that the level of endotoxin and TNF are significantly higher in group I than the other two groups followed by group II. The correlation of endotoxin and TNF alpha with each other and with liver enzymes in group I patients was highly significant as shown in Table 4. Table 5 shows that the correlation of TNF and endotoxin levels with each other and with ALT in group II

Table 1. Demographic data.

\begin{tabular}{|c|c|c|c|c|c|c|}
\hline & & $\begin{array}{l}\text { Group I } \\
\mathrm{N}=32\end{array}$ & $\begin{array}{c}\text { Group II } \\
\mathrm{N}=40\end{array}$ & $\begin{array}{c}\text { Group III } \\
N=20\end{array}$ & $\mathbf{P}$ & Signif. \\
\hline \multicolumn{2}{|c|}{ Age (years) } & $36.1 \pm 8.4$ & $41.1 \pm 9.6$ & $40.1 \pm 8.6$ & $>0.05$ & NS \\
\hline \multirow{2}{*}{ Gender } & Male & $17(53.12 \%)$ & $18(45 \%)$ & $10(50 \%)$ & \multirow{2}{*}{$>0.05$} & \multirow{2}{*}{ NS } \\
\hline & Female & $15(46.87 \%)$ & $22(55 \%)$ & $10(50 \%)$ & & \\
\hline \multicolumn{2}{|c|}{ BMI $\left(\mathrm{kg} / \mathrm{m}^{2}\right)$} & $23.7 \pm 3.4^{\mathrm{a}}$ & $36.8 \pm 4.2^{\mathrm{b}}$ & $27.0 \pm 6.0^{\mathrm{a}}$ & $<0.001$ & HS \\
\hline
\end{tabular}

Values with common subscript letters have no significant difference.

Table 2. Comparison between the two groups as regards laboratory data.

\begin{tabular}{lccccc}
\hline & $\begin{array}{c}\text { Group I } \\
\mathbf{N}=\mathbf{3 2}\end{array}$ & $\begin{array}{c}\text { Group II } \\
\mathbf{N}=40\end{array}$ & $\begin{array}{c}\text { Group III } \\
\mathbf{N}=20\end{array}$ & P & Signif. \\
\hline ALT(IU/L) Mean \pm SD & $67.8 \pm 5.3^{\mathrm{a}}$ & $51.8 \pm 4.2^{\mathrm{b}}$ & $31.5 \pm 3.2^{\mathrm{c}}$ & $<0.001$ & HS \\
AST(IU/L) Mean \pm SD & $62.6 \pm 4.2^{\mathrm{a}}$ & $48.8 \pm 5.8^{\mathrm{b}}$ & $29.5 \pm 2.2^{\mathrm{c}}$ & $<0.001$ & HS \\
$\begin{array}{l}\text { Triglycerides (mg/dl) } \\
\text { Mean } \pm \text { SD }\end{array}$ & $162.4 \pm 34.2^{\mathrm{a}}$ & $222.6 \pm 44.5^{\mathrm{b}}$ & $132.3 \pm 24.4^{\mathrm{c}}$ & $<0.001$ & HS \\
$\begin{array}{l}\text { FBS (mg/dl) Mean } \pm \text { SD } \\
\text { HOMA IR (mg.IU/dl) }\end{array}$ & $82.6 \pm 11.3^{\mathrm{a}}$ & $97.4 \pm 15.7^{\mathrm{b}}$ & $76.4 \pm 6.7^{\mathrm{c}}$ & $<0.001$ & HS \\
Mean \pm SD & $4.2 \pm 1.1^{\mathrm{a}}$ & $4.9 \pm 1.3^{\mathrm{a}}$ & $2.6 \pm 0.7^{\mathrm{c}}$ & $<0.001$ & HS \\
\hline
\end{tabular}

Values with common subscript letters have no significant difference.

Table 3. Comparison between the two groups as regards TNF and endotoxin levels.

\begin{tabular}{lccccc}
\hline & $\begin{array}{c}\text { Group I } \\
\mathrm{N}=32\end{array}$ & $\begin{array}{c}\text { Group II } \\
\mathrm{N}=40\end{array}$ & $\begin{array}{c}\text { Group III } \\
\mathrm{N}=20\end{array}$ & $\mathrm{P}$ & Signif. \\
\hline Endotoxin $(\mathrm{ng} / \mathrm{ml})$ & $11.7 \pm 1.7^{\mathrm{a}}$ & $9.5 \pm 1.4^{\mathrm{b}}$ & $2.7 \pm 0.4^{\mathrm{c}}$ & $<0.001$ & HS \\
TNF $(\mathrm{pg} / \mathrm{ml})$ & $14.8 \pm 5.3^{\mathrm{a}}$ & $11.3 \pm 3.3^{\mathrm{b}}$ & $2.8 \pm 0.7^{\mathrm{c}}$ & $<0.001$ & HS \\
\hline
\end{tabular}

Values with common subscript letters have no significant difference. HS: highly significant. 
Table 4. Relation between TNF and endotoxin with each other and with liver enzymes in group I.

\begin{tabular}{ccccccc}
\hline & \multicolumn{3}{c}{ TNF } & & \multicolumn{3}{c}{ Endotoxin } \\
\cline { 2 - 7 } & $\mathbf{R}$ & $\mathbf{P}$ & Signif. & $\mathbf{R}$ & $\mathbf{P}$ & Signif. \\
\hline ALT & 0.818 & $<0.001$ & HS & 0.983 & $<0.001$ & HS \\
AST & 0.774 & $<0.001$ & HS & 0.934 & $<0.001$ & HS \\
Endotoxin & 0.767 & $<0.001$ & HS & & & \\
\hline
\end{tabular}

HS: Highly significant $\mathrm{P}<0.001$.

Table 5. Relation between TNF and endotoxin with each other and with liver enzymes in group II.

\begin{tabular}{ccccccc}
\hline & \multicolumn{3}{c}{ TNF } & \multicolumn{3}{c}{ Endotoxin } \\
\cline { 2 - 7 } & R & P & Signif. & R & P & Signif. \\
\hline ALT & 515 & $\mathbf{0 . 0 0 5}$ & S & 0.511 & 0.005 & S \\
AST & 0.411 & $\mathbf{0 . 0 9 1}$ & NS & 0.454 & 0.191 & NS \\
Endotoxin & 0.557 & $\mathbf{0 . 0 0 5}$ & S & & & \\
\hline
\end{tabular}

S: Significant $\mathrm{P}<0.05$, NS: non significant $\mathrm{P}>0.05$.

was significant but yet not as that in group I. The correlation of these two to AST in group II was non-significant.

\section{Discussion}

The understanding of the mechanism of development of NFLD especially the GUT barrier, endotoxemia and inflammation can give us new ideas for strategies of treatment.

The pathogenesis of NAFLD/NASH is still obscure. However, the role of obesity, insulin resistance and hyperlipidemia is confirmed by most of the researchers. In the past decade, many studies were published about NAFLD in lean weighted Asian individuals. In our study we wanted to shed light on NAFLD in non-obese Egyptian patients.

In our study we found that group I non-obese patient had significantly higher liver enzymes level than group II obese group. This is in agreement with Wattacheril and Sanyal, 2016 who found that lean patients with NAFLD had even higher mortality rates than obese patients. [15]. This also agree with Alam et al, 2014 who found NASH in 53\% of lean weighted patients with NAFLD [16]. Our study shows that the mean HOMA IR value in non-obese patients wasn't significantly lower than that in obese patients. This means that the incidence of insulin resistance among the lean weighted patients was comparable to that among obese patients. This evident insulin resistance must have participated in the pathogenesis of NAFLD in those patients even without obesity. This finding agrees with Das and Chowdhury, 2013 who gave this condition a nomenclature as "lean NASH" and said that although as regards their body mass index and ab- 
dominal circumference these patients seem lean weighted, they are metabolically obese as regards insulin resistance and metabolic syndrome [17].

Endotoxin level was significantly higher in patients groups I and II than the control group. this in agreement with Jarrar et al., 2008, with who reported that circulating endotoxin levels are elevated in patients with NAFLD. This result supports the idea that chronic endotoxaemia may be an important pathogenic factor in NAFLD and that elevation of endotoxin level may become an early biomarker for potential liver damage also we found that the endotoxin level in group I was significantly higher than group II [18]. This disagrees with Sabate $\boldsymbol{e t}$ al., 2008 who said that obese patients had higher risk of small bowel bacterial overgrowth (SIBO) and that SIBO was related to more severe hepatic steatosis in those patients. This disagreement may be because Sabate studied SIBO as a condition that may result in endotoxemia and didn't study endotoxemia itself although he said that the severe steatosis may be due to absorption of excess endotoxin from gut [7]. Miele et al., studied the alteration in gut permeability in those patients and described the leaky gut associated with SIBO [8].

The level of TNF was also significantly higher in group I patients. This elevation coincides with the higher level of liver enzymes seen in these patients. The excessive expression of TNF is associated with more evident inflammation and necrosis in the liver which led to higher enzymes level in non-obese patients. This agrees with Jarrar et al., 2008, who found that among all the cytokines and adipokines he studied in his study on NAFLD/NASH patients TNF was the only independent predictor of fibrosis in NASH being highly related to liver injury [18].

When we studied the correlation between the TNF and endotoxin levels in non-obese patient we found a highly significant correlation between them. This could mean that the excessive expression of TNF in this group is strongly related to the endotoxemia.

TNF and endotoxin had also highly significant correlation to both ALT and AST levels. This means that the inflammation of the liver is strongly related to endotoxemia and TNF level. Our study agrees with Ceccarelli et al., 2015 who said that endotoxin level and the resultant elevation of TNF alpha are related to the severity of inflammation evident in liver histopathology [19]. This disagrees with Du Plessis et al., 2016 who said that the correlation of endotoxin to inflammatory liver parameters including enzymes wasn't clear however the TNF had strong relation to hepatic inflammation parameters [20].

In the obese patient group the correlation between TNF and endotoxemia was significant. This agrees with Ruiz et al., 2007 who said that endotoxin level and TNF expression are increased in obese patients with NAFLD [21]. However, when compared to their relation in the non-obese group, they were less correlated to each other.

In the obese group, While ALT level was correlated to TNF and endotoxemia significantly but the correlation wasn't as that seen in in non-obese patients group, we found that the AST level wasn't correlated to TNF or to endotoxin 
level which mean that the liver injury in obese patients is not only related to Endotoxin/TNF.

\section{Conclusion}

Endotoxin released from gut flora and TNF released in response to endotoxemia may play a role in the pathogenesis of NAFLD which should be considered in management of those patients.

\section{Recommendations}

Patients with NAFLD specifically those who are lean weighted may benefit from using probiotics or antibiotics to modify their gut flora growth.

\section{References}

[1] Rinella, M.E. (2015) Nonalcoholic Fatty Liver Disease: A Systematic Review. JAMA (Systematic Review), 313, 2263-2273. https://doi.org/10.1001/jama.2015.5370

[2] McCulough, A.J. (2004) The Clinical Features, Diagnosis and Natural History of Nonalcoholic Fatty Liver Disease. Clinics in Liver Disease, 8, 521-533. https://doi.org/10.1016/j.cld.2004.04.004

[3] Adams, L.A. and Angulo, P. (2006) Treatment of Non-Alcoholic Fatty Liver Disease. Postgraduate Medical Journal, 82, 315-322. https://doi.org/10.1136/pgmj.2005.042200

[4] Petersen, K.F., Dufour, S., Hariri, A., Nelson-William, C., Foo, J.N., Zhang, X., Dziura, J., Lifton, R.P. and Shulman, G.I. (2010) Apolipoprotein C3 Gene Variants in Nonalcoholic Fatty Liver Disease. The New England Journal of Medicine, 362, 1082-1089. https://doi.org/10.1056/NEJMoa0907295

[5] Liu, C.J. (2012) Prevalence and Risk Factors for Non-Alcoholic Fatty Liver Disease in Asian People Who Are Not Obese. Journal of Gastroenterology and Hepatology, 27, 1555-1560. https://doi.org/10.1111/j.1440-1746.2012.07222.x

[6] Das, K., Das, K., Mukherjee, P.S., Ghosh, A., Ghosh, S., Mridha, A.R., Dhibar, T., Bhattacharya, B., Bhattacharya, D., Manna, B., Dhali, G.K., Santra, A. and Chowdhury, A. (2010) Nonobese Population in a Developing Country Has a High Prevalence of Nonalcoholic Fatty Liver and Significant Liver Disease. Hepatology, 51, 1593-1602. https://doi.org/10.1002/hep.23567

[7] Sabaté, J.M., Jouët, P., Harnois, F., Mechler, C., Msika, S., Grossin, M. and Coffin, B. (2008) High Prevalence of Small Intestinal Bacterial Overgrowth in Patients with Morbid Obesity: A Contributor to Severe Hepatic Steatosis. Obesity Surgery, 18, 371-377. https://doi.org/10.1007/s11695-007-9398-2

[8] Miele, L., Valenza, V., La Torre, G., Montalto, M., Cammarota, G., Ricci, R., Mascianà, R., Forgione, A., Gabrieli, M.L., Perotti, G., Vecchio, F.M., Rapaccini, G., Gasbarrini, G., Day, C.P. and Grieco, A. (2009) Increased Intestinal Permeability and Tight Junction Alterations in Nonalcoholic Fatty Liver Disease. Hepatology, 49, 1877-1887. https://doi.org/10.1002/hep.22848

[9] Harte, A.L., da Silva, N.F., Creely, S.J., McGee, K.C., Billyard, T., Youssef-Elabd, E.M., Tripathi, G., Ashour, E., Abdalla, M.S., Sharada, H.M., Amin, A.I., Burt, A.D., Kumar, S., Day, C.P. and McTernan, P.G. (2010) Elevated Endotoxin Levels in Non-Alcoholic Fatty Liver Disease. Journal of Inflammation (Lond), 7, 15. https://doi.org/10.1186/1476-9255-7-15

[10] Akira, S., Uematsu, S. and Takeuchi, O. (2006) Pathogen Recognition and Innate 
Immunity. Cell, 124, 783-801. https://doi.org/10.1016/j.cell.2006.02.015

[11] Kiziltas, S. (2016) Toll-Like Receptors in Pathophysiology of Liver Diseases. World Journal of Hepatology, 8, 1354-1369. https://doi.org/10.4254/wjh.v8.i32.1354

[12] Rivera, C.A., Adegboyega, P., van Rooijen, N., Tagalicud, A., Allman, M. and Wallace, M. (2007) Toll-Like Receptor-4 Signaling and Kupffer Cells Play Pivotal Roles in the Pathogenesis of Non-Alcoholic Steatohepatitis. Journal of Hepatology, 47, 571-579. https://doi.org/10.1016/j.jhep.2007.04.019

[13] Hegazy, M. and Mostafa, A. (2012) Liver Ultrasound Scanning in the Detection of Hepatic Steatosis and Fibrosis in NASH Patients. The Egyptian Journal of Internal Medicine, 24, 27-31.

[14] Matthews, D.R., Hosker, J.P., Rudenski, A.S., Naylor, B.A., Treacher, D.F. and Turner, R.C. (1985) Homeostasis Model Assessment: Insulin Resistance and Beta-Cell Function from Fasting Plasma Glucose and Insulin Concentrations in Man. Diabetologia, 28, 412-419. https://doi.org/10.1007/BF00280883

[15] Wattacheril, J. and Sanyal, A.J. (2016) Lean NAFLD: An Underrecognized Outlier. Current Hematology Reports, 15, 134-139. https://doi.org/10.1007/s11901-016-0302-1

[16] Alam, S., Gupta, U.D., Alam, M., Kabir, J., Chowdhury, Z.R. and Alam, A.K. (2014) Clinical, Anthropometric, Biochemical, and Histological Characteristics of Nonobese Nonalcoholic Fatty Liver Disease Patients of Bangladesh. Indian Journal of Gastroenterology, 33, 452-457. https://doi.org/10.1007/s12664-014-0488-5

[17] Das, K. and Chowdhury, A. (2013) Lean NASH: Distinctiveness and Clinical Implication. Hepatology International, 7, 806-813.

[18] Jarrar, M.H., Baranova, A., Collantes, R., Ranard, B., Stepanova, M., Bennett, C., Fang, Y., Elariny, H., Goodman, Z., Chandhoke, V. and Younossi, Z.M. (2008) Adipokines and Cytokines in Non-Alcoholic Fatty Liver Disease. Alimentary Pharmacology \& Therapeutics, 27, 412-421. https://doi.org/10.1111/j.1365-2036.2007.03586.x

[19] Ceccarelli, S., Panera, N., Mina, M., Gnani, D., De Stefanis, C., Crudele, A., Rychlicki, C., Petrini, S., Bruscalupi, G., Agostinelli, L., Stronati, L., Cucchiara, S., Musso, G., Furlanello, C., Svegliati-Baroni, G., Nobili, V. and Alisi, A. (2015) LPS-Induced TNF- $\alpha$ Factor Mediates Pro-Inflammatory and Pro-Fibrogenic Pattern in Non-Alcoholic Fatty Liver Disease. Oncotarget, 6, 41434-41452.

[20] duPlessis, J., Korf, H., van Pelt, J., Windmolders, P., Vander Elst, I., Verrijken, A., Hubens, G., Van Gaal, L., Cassiman, D., Nevens, F., Francque, S., and van der Merwe, S. (2016) Pro-Inflammatory Cytokines but Not Endotoxin-Related Parameters Associate with Disease Severity in Patients with NAFLD. PLoS ONE, 11, e0166048

[21] Ruiz, A.G., Casafont, F., Crespo, J., Cayón, A., Mayorga, M., Estebanez, A., Fernadez-Escalante, J.C. and Pons-Romero, F. (2007) Lipopolysaccharide-Binding Protein Plasma Levels and Liver TNF-Alpha Gene Expression in Obese Patients: Evidence for the Potential Role of Endotoxin in the Pathogenesis of Non-Alcoholic Steatohepatitis. Obesity Surgery, 17, 1374-1380.

https://doi.org/10.1007/s11695-007-9243-7 
Submit or recommend next manuscript to SCIRP and we will provide best service for you:

Accepting pre-submission inquiries through Email, Facebook, LinkedIn, Twitter, etc. A wide selection of journals (inclusive of 9 subjects, more than 200 journals)

Providing 24-hour high-quality service

User-friendly online submission system

Fair and swift peer-review system

Efficient typesetting and proofreading procedure

Display of the result of downloads and visits, as well as the number of cited articles Maximum dissemination of your research work

Submit your manuscript at: http://papersubmission.scirp.org/

Or contact jbm@scirp.org 